\title{
Overview of Post Approval Changes Requirements for Active Pharmaceutical Ingredients in Canada, Australia and Saudi Arabia
}

\author{
Mausami Vaghela ${ }^{1,2,{ }^{*},}$ Pankaj Kapupara ${ }^{1}$ \\ 'School of Pharmacy, RK University, Rajkot, Gujarat, INDIA. \\ 2Department of Pharmaceutical Sciences, Saurashtra University, Rajkot, Gujarat, INDIA.
}

\begin{abstract}
Regardless of a product's country of registration, a current and updated pharmaceutical product dossier is mandatory. But any kind of post-approval change to pharmaceutical products requires prior permission or at least notification to the regulatory authorities of the country. The reason behind the post approval changes may vary including product quality advancement, reduction of cost or improvement of the appearance of a product label, etc. As it is compulsory to provide the details of post-approval changes made in pharmaceutical products, thorough knowledge of guidance documents of concerned regulatory authority is vital. Therefore, understanding a need for post-approval changes together with avoiding any unnecessary changes is an integral part of the medicinal product's lifecycle management. Not only the changes of finished pharmaceutical products, but regulatory authorities also concern about the necessity of changes of active pharmaceutical ingredients, as these changes may impact on finished product's quality. The
\end{abstract}

present article focuses on a comprehensive review of the requirements of post-approval changes related to active pharmaceutical ingredients for Canada, Australia, and Saudi Arabia, which may help pharmaceutical industries to comply with the requirements simultaneously in the proposed countries.

Key words: Variation, Changes in Registered Product, API, Drug Substance, Regulated Market, Emerging Market, GCC Country.

\section{Correspondence}

Ms. Mausami Vaghela

Assistant Professor, Department of Pharmaceutical Sciences, Saurashtra University, Rajkot-360005, Gujarat, INDIA.

Email id: mausami_2123@yahoo.com

DOI: 10.5530/ijpi.2021.4.62

\section{INTRODUCTION}

Post-approval changes are also termed Variation. Changes in pharmaceutical product aspects like change to the manufacturing process, manufacturing site, specification of the finished product or active substance, container closure system or label, etc. are crucial. ${ }^{1}$ Once a pharmaceutical product is registered with the regulatory authority of the country, the manufacturer cannot change any aspects related to a registered product without any prior intimation or sometimes required approval. The reason behind the changes may vary widely, which includes updated product information, improvement in the quality of product, advancement in technical processes of product manufacturing, enhancement of shelf-life, etc. ${ }^{2,3}$ Depending on the type of change, the amount of data needed and the mechanism of application to regulatory authorities varies. Therefore, a manufacturer needs to refer to the guidelines specific to the jurisdiction in order to follow the proper compliance procedures. ${ }^{1,4}$

There are numerous studies found which describe the variation requirements of finished pharmaceutical products (FPP) by different regulatory authorities, but very few highlights the variation requirements related to API. It is estimated that the API market size will reach $\$ 312.56$ billion by the year 2028. As per the expert's opinion, this market is estimated to develop by $6.6 \%$ CAGR in the forecast period. Not only the major API markets but smaller markets are also increasing their API manufacturing facilities. ${ }^{5}$ The Canadian authority provided new regulations which apply to all API manufacturers. These new rules were anticipated to provide a net benefit of around $\$ 33.4$ million over 10 years to the manufacturers. ${ }^{6}$ Whereas, CSL Australia was found to be one of the key players of the API market in 2019. Apart from biologicals, the
API market of Australia includes alkaloids, flavonoids, extraction of bioactive, biopharmaceuticals, etc. that will increase the growth of the API market in Australia. ${ }^{78}$ Not only to the regulated market but the present review work focuses on the emerging market like Saudi Arabia as well. One of the attractive markets for pharmaceuticals in the Middle East region is Saudi Arabia. It has an oil-based economy, and due to less oil prices, the Saudi government mainly focuses on the development of their healthcare sector. The pharmaceutical market of Saudi Arabia was valued at USD 8.3 billion in 2019 and forecasts show, it will be projected to grow USD 10.89 billion by 2024. Furthermore, API market growth is increasing rapidly with increasing prevalence of various chronic disorders. ${ }^{9-11}$ With tremendous opportunities for the development in these countries, not avoiding their strict regulations, to learn about the regulatory requirements especially for the post-approval changes of APIs are worth studying for.

\section{CANADA}

Health Canada is a regulatory authority of Canada. It has provided guidelines related to post-approval changes under the title "Post-Notice of Compliance (NOC) Changes: Quality Document". This guidance document was adopted in September 2009, but thereafter it was updated several times. This guidance document assists with the quality changes classification in respect to the new drug. It also provides recommendations on data and support to changes which would be considered sufficient to allow determination of the impact of changes on the quality of new drug as these changes may affect the safety as well as efficacy profile of a new drug. ${ }^{12}$ Apart from this, other relevant guidance

This is an open access article distributed under the terms of the Creative Commons Attribution-NonCommercial-ShareAlike 4.0 License, which allows others to remix, tweak, and build upon the work non-commercially, as long as the author is credited and the new creations are licensed under the identical terms. 
documents given by Health Canada includes "Post Notice of Compliance Changes - Framework Document" and "Post Notice of Compliance Changes - Safety and Efficacy Document". ${ }^{13,14}$

\section{Classification of Post Approval Changes}

There is a different level of changes described by Health Canada. Table 1 shows these types of changes. Variation guideline describes that Level 1 type of changes is usually supported by in-vivo studies. Whereas for level 3 change supporting data are usually not submitted to Health Canada, however, if requested, it should be submitted within 30 calendar days. Changes covered as level 4 are retained as a part of the product's record by either sponsor or manufacturer and comply with Good Manufacturing Practice (GMP) requirements of regulations of the country.

Health Canada describes various post-approval changes related to active substance includes the change in name of active substance, manufacturing site replacement, addition or deletion, active substance batch size change, change in control of active substance, primary container closure system, label, shelf life, etc. ${ }^{12,15}$

\section{AUSTRALIA}

Australian Regulatory Authority is known as Therapeutic Goods Administration (TGA). It provides various guidelines related to postmarketing changes namely, "Variations to Prescription Medicines excluding Variations requiring Evaluation of Clinical or Bioequivalence Data, Appendix 1: Variation Types - Chemical Entities", "Minor Variations to prescription medicines - Process Guidance", "Variations to Prescription Medicines - excluding Variations requiring Evaluation of Clinical or Bioequivalence Data, Appendix 2: Variation Types Biological Medicines" and "Variations to Prescription Medicines excluding Variations requiring Evaluation of Clinical or Bioequivalence Data - Process Guidance". ${ }^{16-20}$ The guideline related to post-approval changes related to API are mainly described in the variation guidance document given for chemical entities. ${ }^{16}$

In Australia, once a product is registered in ARTG, the information given during the registration cannot be changed without approval from the authority. In case of any breaching of provisions of the act, penalties may apply including suspension or cancellation of registration of a product.

\section{Classification of Post Approval Changes}

Under the provision of the s.9D act, there are four different kinds of requests which can be made to the authority to seek approval for change in registered prescription medicine.
1. Subsection 9D(1) permits an incomplete or incorrect ARTG entry updation.

2. Subsection $9 \mathrm{D}(2)$ permits ARTG entry changes related to the safety of the product as well as sequential changes into the finished pharmaceutical product. For example, patient population reduction by removing an indication or adding a warning or precaution, etc.

3. Subsection $9 \mathrm{D}(2 \mathrm{C})$ allows changes to ARTG entry which does not affect safety, efficacy, and quality of medicine. These kinds of changes require approval from TGA under certain conditions.

4. Subsection $9 \mathrm{D}(3)$ permits change requests which do not have the effect of creating a separate and distinct product. The only condition is that these kinds of changes should not reduce the safety, efficacy, and quality of prescription medicine. Changes made under subsection $9 \mathrm{D}(3)$ sometimes involve sequential changes to product information.

Apart from these, TGA has described various categories of variation including Correction to an ARTG entry, notification, quality information containing self-assessable requests (SARs) and category 3 requests, product information related variation consists of minor editorial changes (MEC), Safety related requests (SRRs) and extension of indication to align with a reference product. ${ }^{17,19}$

TGA also describes the time frame for different kinds of changes depending on the level of assessment required in the variation application. Different kind of application categories and their level of assessment is summarized in Table 2. Moreover, for the description of various possible changes in the registered product, TGA has specified three different variation types:

1. Multiple Related Changes

2. Multiple Unrelated Changes

3. Associated Changes

Sometimes, varying one aspect of a product may result in the need for change in another information. For example, a change in storage condition also requires a change in the product label. These kinds of changes are called Multiple Related Changes. In this case, one consolidated single application considering all the related changes is feasible rather than selecting a separate variation type for each of these changes. TGA also provides the opportunity to request multiple unrelated changes in a single application type, known as Multiple Unrelated Changes. For example, for changes in a label, one change requires only notification whereas another change requires evaluation by the regulatory body. In this case, a single Category 3 application request can be submitted to TGA for evaluation of proposed label changes. Moreover, TGA gives

Table 1: Types of Post Approval Changes in Canada. ${ }^{12}$

\begin{tabular}{|c|c|c|c|c|}
\hline Level of Change & Level 1 & Level 2 & Level 3 & Level 4 \\
\hline Also known as & Supplements & Notifiable Change & Annual Notification & Record of Changes \\
\hline Type of Change & Major & Moderate & Minor & Minor \\
\hline Description & $\begin{array}{l}\text { Changes having considerable } \\
\text { potential to have an impact on } \\
\text { the strength, identity, purity, } \\
\text { quality, or potency of a drug }\end{array}$ & $\begin{array}{l}\text { Changes having the moderate } \\
\text { potential to have an impact on } \\
\text { the strength, identity, purity, } \\
\text { quality, or potency of a drug }\end{array}$ & $\begin{array}{c}\text { Changes having less potential to } \\
\text { have an impact on the strength, } \\
\text { identity, purity, quality, or } \\
\text { potency of a drug }\end{array}$ & $\begin{array}{l}\text { Changes to a new drug that are } \\
\text { not level } 1,2 \text {, or } 3 \text {. These kinds } \\
\text { of changes do not adversely } \\
\text { affect the strength, identity, } \\
\text { purity, quality, or potency of } \\
\text { a drug }\end{array}$ \\
\hline Requirements & $\begin{array}{l}\text { No Objection Certificate } \\
\text { (NOC) required }\end{array}$ & $\begin{array}{l}\text { No Objection Letter (NOL) by } \\
\text { the regulatory authority }\end{array}$ & $\begin{array}{l}\text { Supporting data (if asked by } \\
\text { authority) }\end{array}$ & - \\
\hline Implementation & After approval by the authority & After approval by the authority & $\begin{array}{l}\text { Without prior review by the } \\
\text { authority }\end{array}$ & $\begin{array}{l}\text { Without prior review by the } \\
\text { authority }\end{array}$ \\
\hline
\end{tabular}


Table 2: Post-approval Change Application Category and Their Level of Assessment by TGA. ${ }^{17}$

\begin{tabular}{|c|c|}
\hline Application Category & Level of Assessment \\
\hline $\begin{array}{c}\text { Correction or completion in ARTG } \\
\text { entry }\end{array}$ & Verification of details provided \\
\hline $\begin{array}{c}\text { Modification request to vary an } \\
\text { ARTG entry }\end{array}$ & No assessment \\
\hline $\begin{array}{c}\text { Self-assessable request to vary ARTG } \\
\text { entry }\end{array}$ & Verification of details provided \\
\hline Safety-related request & Verification of details provided \\
\hline $\begin{array}{c}\text { Category } 3 \text { request - variation to } \\
\text { ARTG entry }\end{array}$ & Quality data evaluation \\
\hline Safety-related request with data & Evaluation of data submitted to TGA \\
\hline $\begin{array}{c}\text { Category } 1 \text { application: Variation to } \\
\text { ARTG entry with consequential PI } \\
\text { change }\end{array}$ & $\begin{array}{l}\text { Full evaluation of quality, } \\
\text { bioequivalence, clinical and non- } \\
\text { clinical data }\end{array}$ \\
\hline
\end{tabular}

provision to change an existing product which may result in new and distinct goods and that may require other variations to be included. This kind of variation is called Associated Changes for separate and distinct goods. A single application is sufficient with the required data for the "Associated Changes" type of variation. ${ }^{19,20}$

Therapeutic Goods Administration describes various post-approval changes related to active pharmaceutical ingredient including change of marketing authorization holder of API, replacement or addition of manufacturing site, deletion of manufacturing site, change in a manufacturing process, change in control of API, primary container closure system, label, shelf life, etc. ${ }^{16}$

\section{SAUDI ARABIA}

Saudi Arabia is one of the countries of the Gulf Cooperation Council (GCC). Therefore, it follows various guidelines given by GCC. For APIrelated variation requirements, the Saudi Food and Drug Authority (SFDA) follows a guideline titled "The GCC Guidelines for Variation Requirements".

\section{Classification of Post Approval Changes}

The type of changes provided by GCC countries is described in Table 3. Notification to SFDA within 60 working days after the implementation of Type IA changes is mandatory in Saudi Arabia. Whereas, type IB changes do not require formal approval from the authority. It is recommended that the marketing authorization holder should wait for 120 working days before implementing the proposed change to ensure that the application is accepted by the regulatory authority.

Saudi Food and Drug Administration outlines various post-approval changes related to active substances, which includes the change in name of a marketing authorization holder, change in name of API, ATC code, deletion of manufacturing site, batch size change, change in a manufacturing process, change in control of API, primary container closure system, shelf life, etc.

Requirement of a new application for the changes related to API is also discussed in the guideline, which includes Change of API to different API, Inclusion of additional API, Removal of one API from a multicomponent product, Change from immediate release from Extended-release, Change in dosage form and Change in route of administration..$^{21,22}$

\section{DISCUSSION}

Pharmaceutical industries are the highly regulated and evolving industries. Technological advancement has made it possible to
Table 3: Types of Post-approval Changes in Saudi-Arabia. ${ }^{21}$

\begin{tabular}{|c|c|c|c|}
\hline Type of Change & Minor - Type IA & Minor - Type IB & Major - Type II \\
\hline Level of risk & Low & Low & High \\
\hline Description & $\begin{array}{l}\text { Changes having } \\
\text { fewer effects on } \\
\text { the overall safety, } \\
\text { efficacy, and } \\
\text { quality of the FPP }\end{array}$ & $\begin{array}{l}\text { Changes having } \\
\text { fewer effects } \\
\text { on the overall } \\
\text { safety, efficacy, } \\
\text { and quality of } \\
\text { the FPP }\end{array}$ & $\begin{array}{l}\text { Changes having } \\
\text { considerable } \\
\text { effects on the } \\
\text { overall safety, } \\
\text { efficacy, and } \\
\text { quality of the FPP }\end{array}$ \\
\hline Requirements & $\begin{array}{l}\text { Notify within } 60 \\
\text { working days of } \\
\text { implementation }\end{array}$ & $\begin{array}{l}\text { Notify before } \\
\text { implementation }\end{array}$ & $\begin{array}{l}\text { Supporting } \\
\text { documents }\end{array}$ \\
\hline Implementation & $\begin{array}{l}\text { Without prior } \\
\text { approval by the } \\
\text { authority }\end{array}$ & $\begin{array}{l}\text { Without prior } \\
\text { approval by the } \\
\text { authority }\end{array}$ & $\begin{array}{c}\text { After approval by } \\
\text { the authority }\end{array}$ \\
\hline
\end{tabular}

manufacture pharmaceutical products faster with minimum possible cost. But the only concern is, this ever-changing technological advancement leads to an ever-changing set of marketing authorization applications. ${ }^{1}$ As a minor change may impact the quality of a product, it is necessary to regulate the changes made in the registered products. The crucial part is a change related to active substances, which may alter the quality, safety, and efficacy of the pharmaceutical product. Therefore, to safeguard the quality, safety, and efficacy of pharmaceutical product, constant watch on the changes related to active substance become necessary. The present study shows that the variation filing process in proposed countries are very concise and prominent. Guidelines are created to limit the unnecessary changes to the pharmaceutical products, as these kinds of changes may change the properties of the product and ultimately may rise public health concerns. During the review of the proposed work, it has been found that different countries have different requirements regarding the post-approval changes. Table 4 shows these kinds of changes related to API described in different guidelines of proposed countries.

\section{CONCLUSION}

From the current review work, it can be concluded that there is a vast difference in the post-approval changes requirement guidelines in Canada, Australia, and Saudi Arabia. There are few changes such as replacement or addition of manufacturing site or manufacturer, deletion of manufacturing site, change in the manufacturing process, change in batch size, control of drug substance, change in specification and method of analysis of API, change in primary packing material, shelf-life, etc. are discussed by regulatory authorities of all the proposed countries. These types of changes are those which might have an impact on the quality, safety, and/or efficacy of API and finished product. But there are some changes that are not covered by one or more countries. Such as a change in marketing authorization, change in ATC code, change in specification and method of analysis of primary packing material are not covered by Canada and Australian regulatory authorities. A change in labelled storage condition and submission of TSE information are not mentioned in the guidelines given by regulatory authorities of Australia and Saudi Arabia. Whereas, quality control testing of API at alternative sites and a change to local handling agent of API-related information are not explained by Canada and Saudi Arabian regulatory authorities. Apart from the types of changes discussed by regulatory authorities, the data required in the application of post-approval changes also vary widely. Therefore, it can be concluded that harmonization in these kinds of guidelines can be helpful for pharmaceutical industries. It may lead to timely implementation of guidelines and easy control of changes made in API and ultimately to the finished pharmaceutical product. 
Vaghela and Kapupara.: Post Approval Changes of API

Table 4: List of changes related to API with their type of application given by Canada, Australia, and Saudi Arabia. ${ }^{12,16,21}$

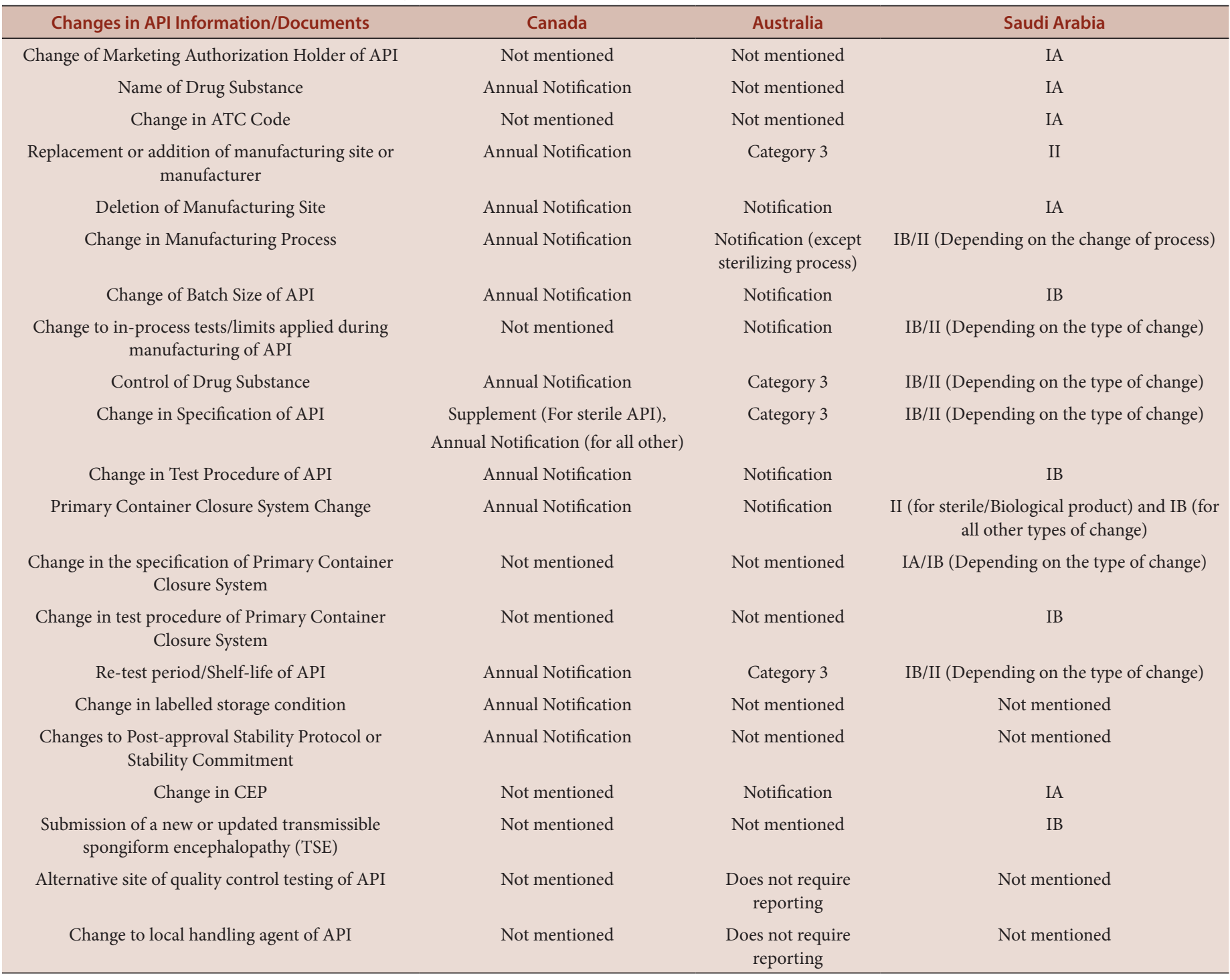

\section{ACKNOWLEDGEMENT}

The authors thank the Department of Pharmaceutical Sciences, Saurashtra University, and School of Pharmacy, RK University for their continuous support and guidance to facilitate this work.

\section{CONFLICT OF INTEREST}

The authors declare that there is no conflict of interest.

\section{REFERENCES}

1. Lokesh MS, Gupta NV, Belagoankar BD. Comparative study of Process of Post Approval Changes Application Submission and Approval for Marketing Authorization Variation in EU, US, India, Saudi Arabia and Singapore. Int J Drug Dev Res. 2015;7(1):10-22.

2. World Health Organization. WHO general guidance on variations to multisource pharmaceutical products; 2015. p. 1-16.

3. Melullis DM. Best practice of worldwide product variations regarding planning, conduct and implementation. 2015.

4. Goswami R, Maheshwari D. Comparative study of regulatory requirements for post approval changes in us, Europe and South Africa J Pharm sci. J Biol Sci Res. 2014;4(1):177-83.

5. Cision PR. Newswire. Active pharmaceutical ingredients market size to reach $\$ 312.56$ billion by 2028 , owing to advancements in API manufacturing and the rising prevalence of chronic diseases - million insights; updated 2021; [cited
Sep 1 2021]. Available from: https://www.prnewswire.com/news-releases/ activepharmaceutical-ingredients-market-size-to-reach-312-56-billion-by-2028-owing-to-advancements-in-api-manufacturing-and-the-rising-prevalence-ofchronicdiseases-m illion-insig hts-301321612.html.

6. Available from: Outsourcing-pharma.com. Canada solidifies GMP requirements for APIs to secure supply chain; updated 2013; [cited Sep 1 2021]. Available from: https://www.outsourcing-pharma.com/Article/2013/05/14/Canada-SolidifiesGMP-Requirements-for-APIs-to-Secure-Supply-Chain.

7. Markets and markets. Market Leader - Active Pharmaceutical Ingredients Market. [cited Sep 1 2021]. Available from: https://www.marketsandmarkets. com/Researchlnsight/API-market.asp.asp.

8. Active Pharmaceutical Ingredient Manufacturer's Association of Australia. Active pharmaceutical ingredients - Australian organisation for quality; updated 2015; [cited Sep 1 2021]. Available from: https://www.yumpu.com/ en/document/view/27683891/active-pharmaceutical-ingredients-australianorganisation-for-quality.

9. Pharmexcil. Saudi Arabia Pharma market and regulatory report; updated 2020; [cited Sep 1 2021]. Available from: https://pharmexcil.com/uploads/ countryreports/SaudiArabia_Market_Regulatory_report2020.pdf.

10. Mordor intelligence. Market entry - active pharmaceutical ingredients (API) industry in Saudi Arabia: analysis of growth, trends and Pregress; 20202025. [updated 2019; [cited Sep 1 2021]. Available from: https://www. mordorintelligence.com/industry-reports/market-entry-active-pharmaceuticalingredients-apiindustry-in-saudi-arabia.

11. Data Bridge Market Research. Middle East and Africa active pharmaceutical ingredients (API) market - industry trends and forecast to 2028 [cited Sep 1 2021]. Available from: https://www.databridgemarketresearch.com/reports/ middle-east-and-africa-active-pharmaceutical-ingredient-api-market. 
12. Health Canada. Guidance document Post - notice of compliance (NOC) changes: Quality document; 2019;1-271.

13. Health Canada. Guidance document Post - notice of compliance (NOC) changes: Framework document; 2018;1-13.

14. Health Canada. Guidance document Post - notice of compliance (NOC) changes: safety and efficacy document; 2019;1-20.

15. Rathod D, Shah J, Maheshwari D. A study on variations in pharmaceutical products in Philippines and variation policies in US, Canada, Australia. J Glob Trends Pharm Sci. 2015;6(1):2340-4.

16. Therapeutics Goods Administration. Variations to prescription medicines excluding variations requiring evaluation of clinical or bioequivalence data, Appendix 1. Variation types - chemical entities. 2020;1-128.

17. Therapeutics Goods Administration. Minor variations to prescription medicines; 2017; 1-32.
18. Therapeutics Goods Administration. Variations to prescription medicines excluding variations requiring evaluation of clinical or bioequivalence data, Appendix 2. Variation types - biological medicines. 2019;1-107.

19. Therapeutics Goods Administration. Variations to prescription medicines excluding variations requiring evaluation of clinical or bioequivalence data, process guidance; 2019;1-40.

20. Therapeutics Goods Administration. Variations to prescription medicines excluding variations requiring the evaluation of clinical or bioequivalence data Australia; 2019.

21. Saudi Food and Drug Authority. The GCC guidelines for variation requirements; 2011;1-63.

22. PharmaKnowl consulting. SFDA variation guidelines overview; Updated 2021; [cited Sep 1 2021]. Available from: https://pharmaknowl.com/sfda-variationguidelines/.

Article History: Submission Date : 10-09-2021; Revised Date : 03-11-2021; Acceptance Date : 04-12-2021.

Cite this article: Vaghela M, Kapupara P. Overview of Post Approval Changes Requirements for Active Pharmaceutical Ingredients in Canada, Australia and Saudi Arabia. Int. J. Pharm. Investigation. 2021;11(4):349-53. 